\title{
Ferrocenylphosphines as New Catalysts for Baylis-Hillman
}

\section{Reaction}

\section{Supporting Information}

\author{
Susana Isabel Pereira, ${ }^{\dagger}$ Javier Adrio, ${ }^{\dagger}$ Artur M. S. Silva, ${ }^{\dagger}$ Juan Carlos Carretero ${ }^{*},{ }^{\dagger}$ \\ Departamento de Química Orgánica, Universidad Autónoma de Madrid. Cantoblanco 28049 Madrid, \\ Spain and Departamento de Química, Universidade de Aveiro, Campus de Santiago. 3810-183 Aveiro, \\ Portugal
}

\section{List of Contents}

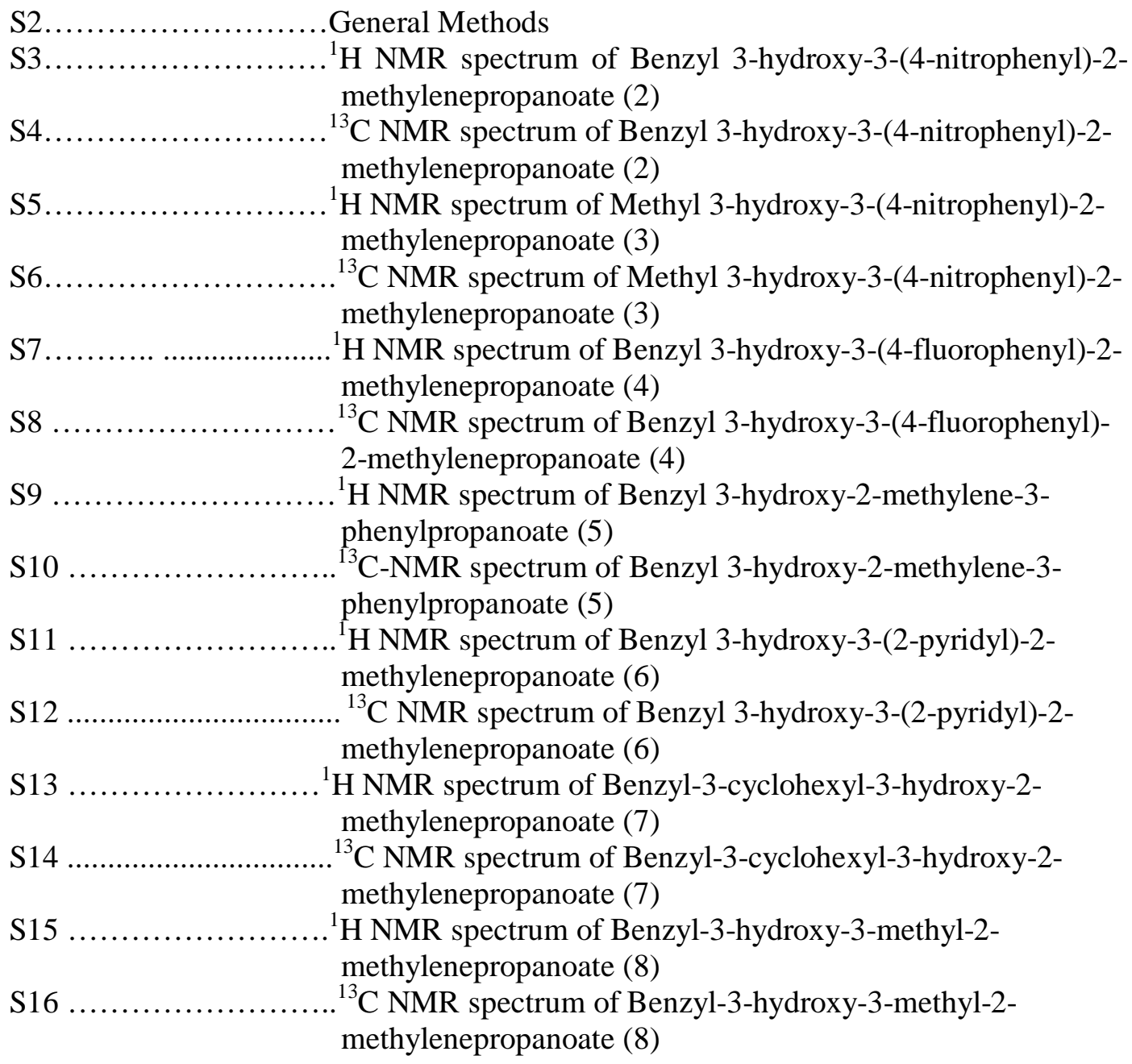


General Methods: All anaerobic and moisture-sensitive manipulations were carried out under nitrogen atmosphere. Dichloromethane, toluene, THF, $\mathrm{CH}_{3} \mathrm{CN}, \mathrm{MeOH}, \mathrm{AcOEt}$ and DMF were dried and stored over microwave-activated $4 \AA$ molecular sieves. Reactions were monitored by thin-layer chromatography carried out on $0.25 \mathrm{~mm}$ silica gel plates. 230-400 mesh silica gel was used for flash column chromatography. The combined organic layers were dried over $\mathrm{Na}_{2} \mathrm{SO}_{4}$. Solvents were evaporated under reduced pressure. All given yields refer to as isolated yields. Optical rotations were measured on a precision automated polarimeter. NMR spectra were recorded on 200 or $300 \mathrm{MHz}$ instruments and calibrated using residual undeuterated solvent $\left(\mathrm{CDCl}_{3}\right)$ as internal reference. IR spectra were recorded on a FT-IR spectrometer. MS and HRMS experiments were performed on high/low resolution magnetic sector mass spectrometer. 


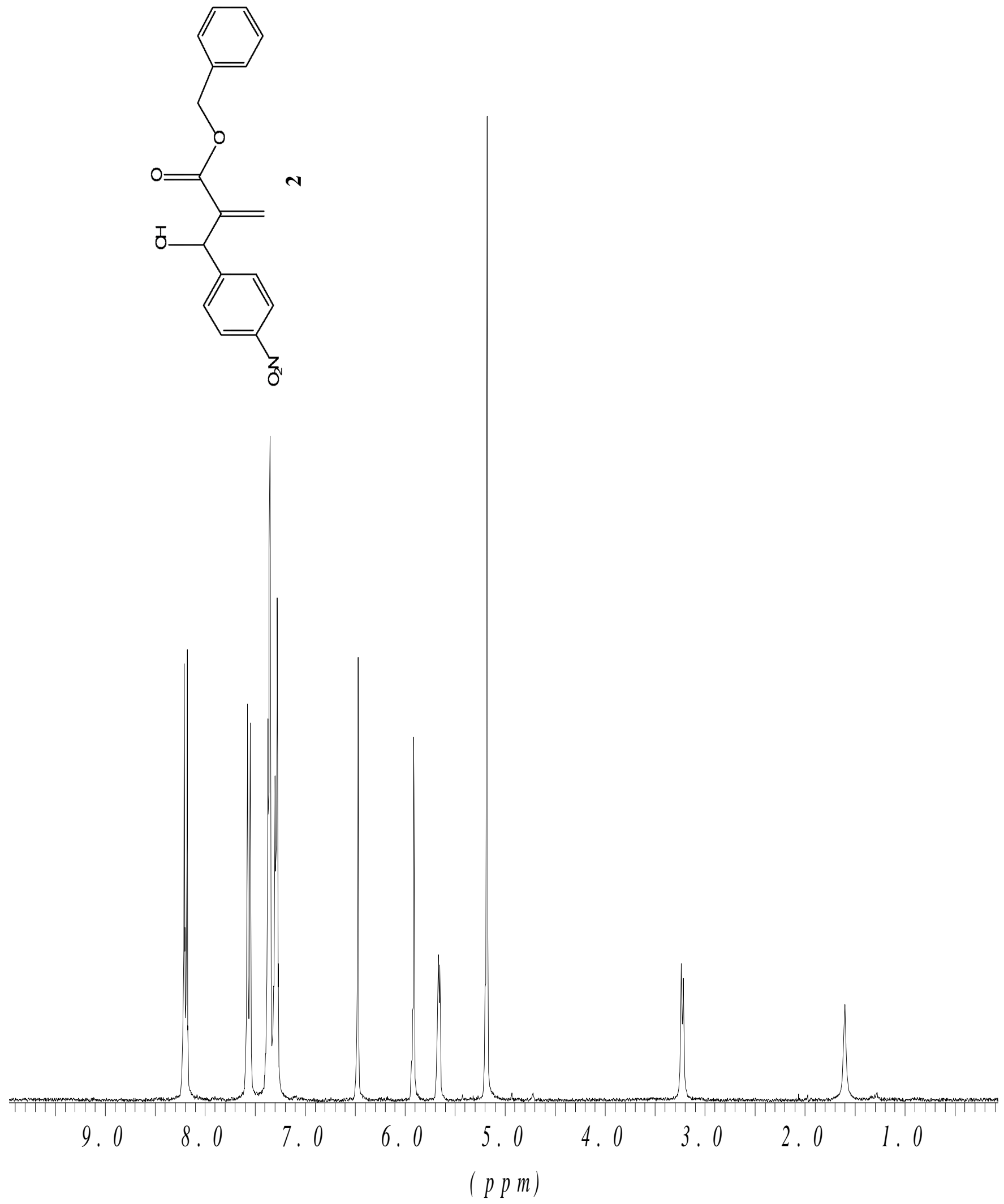




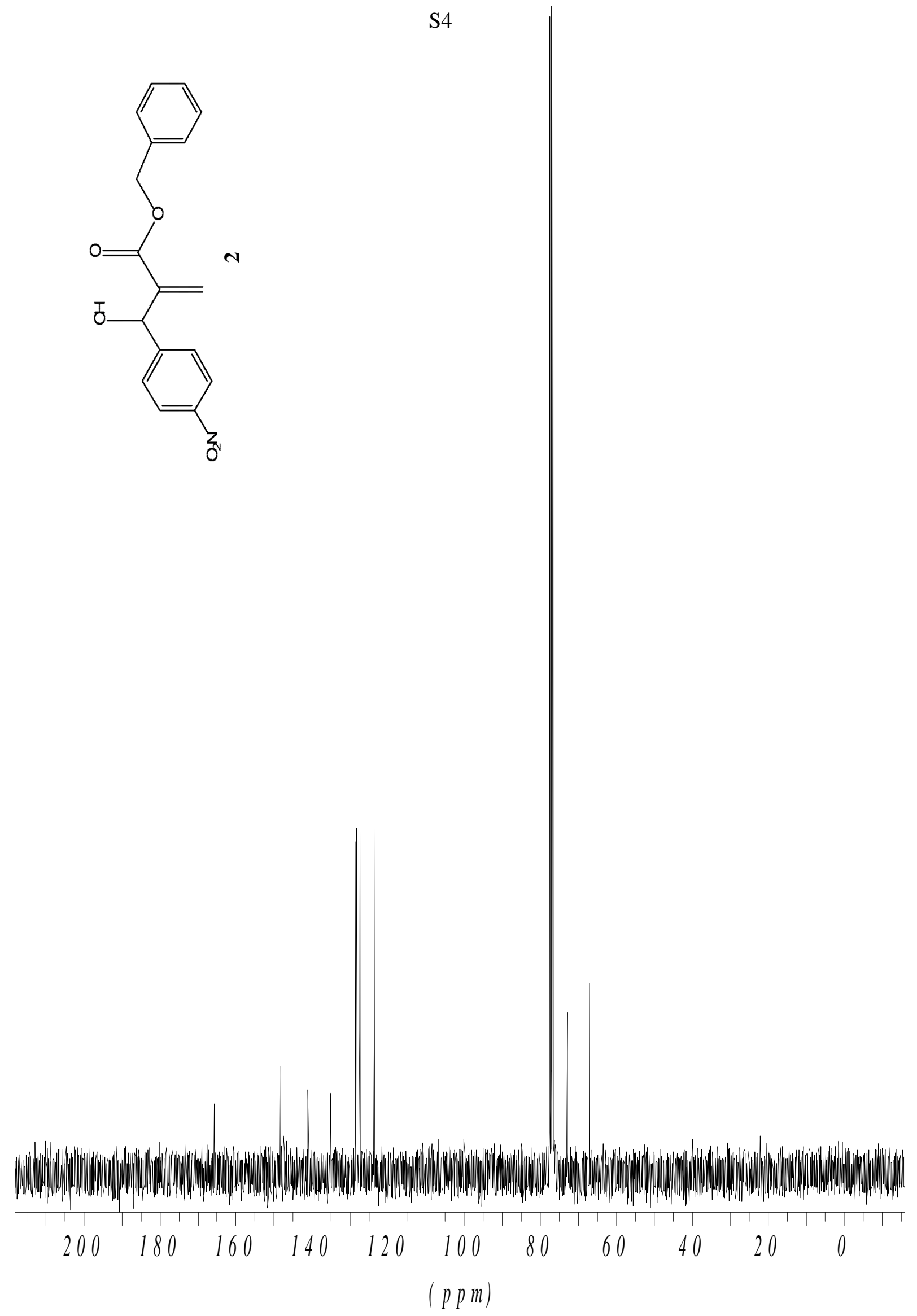



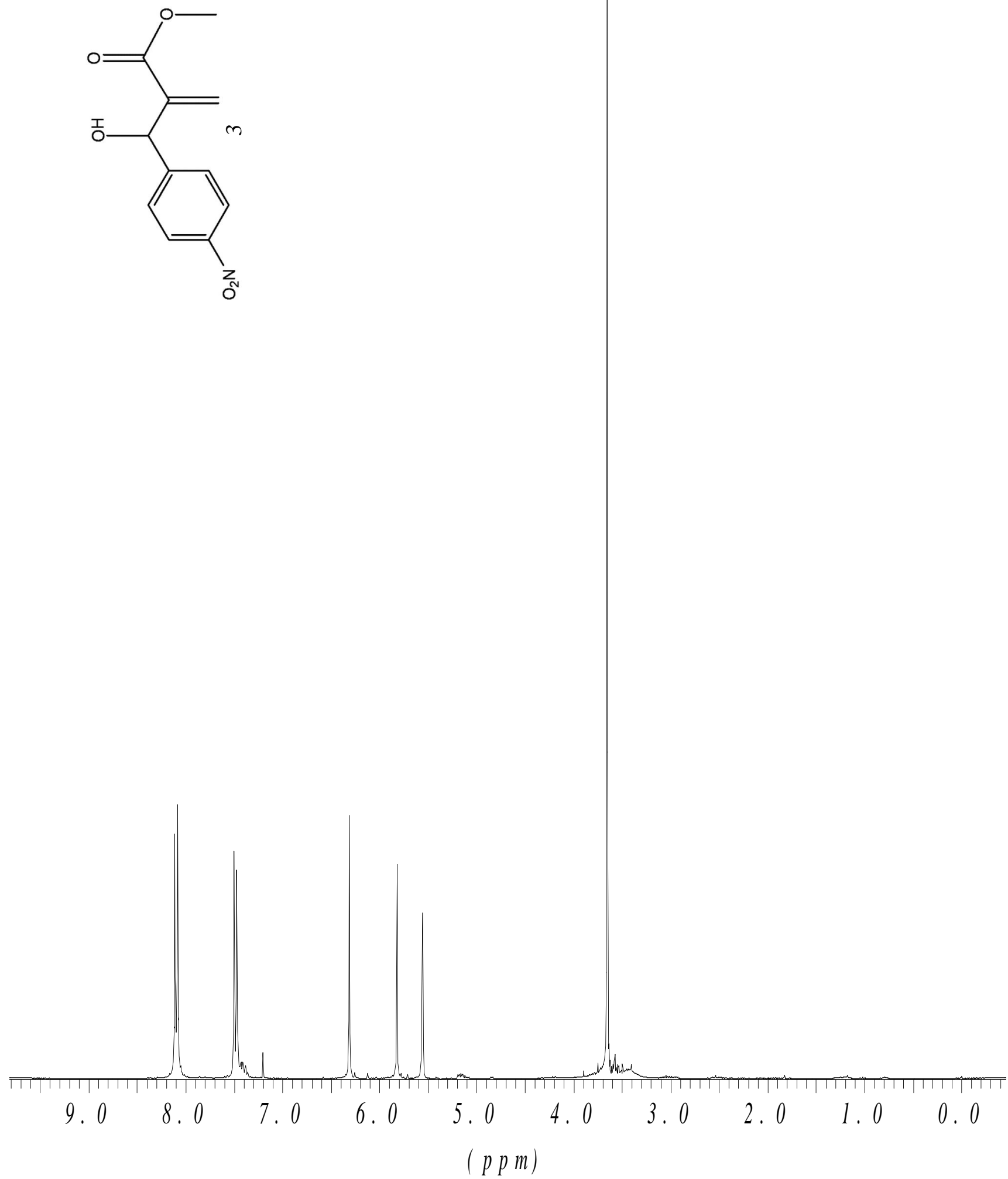


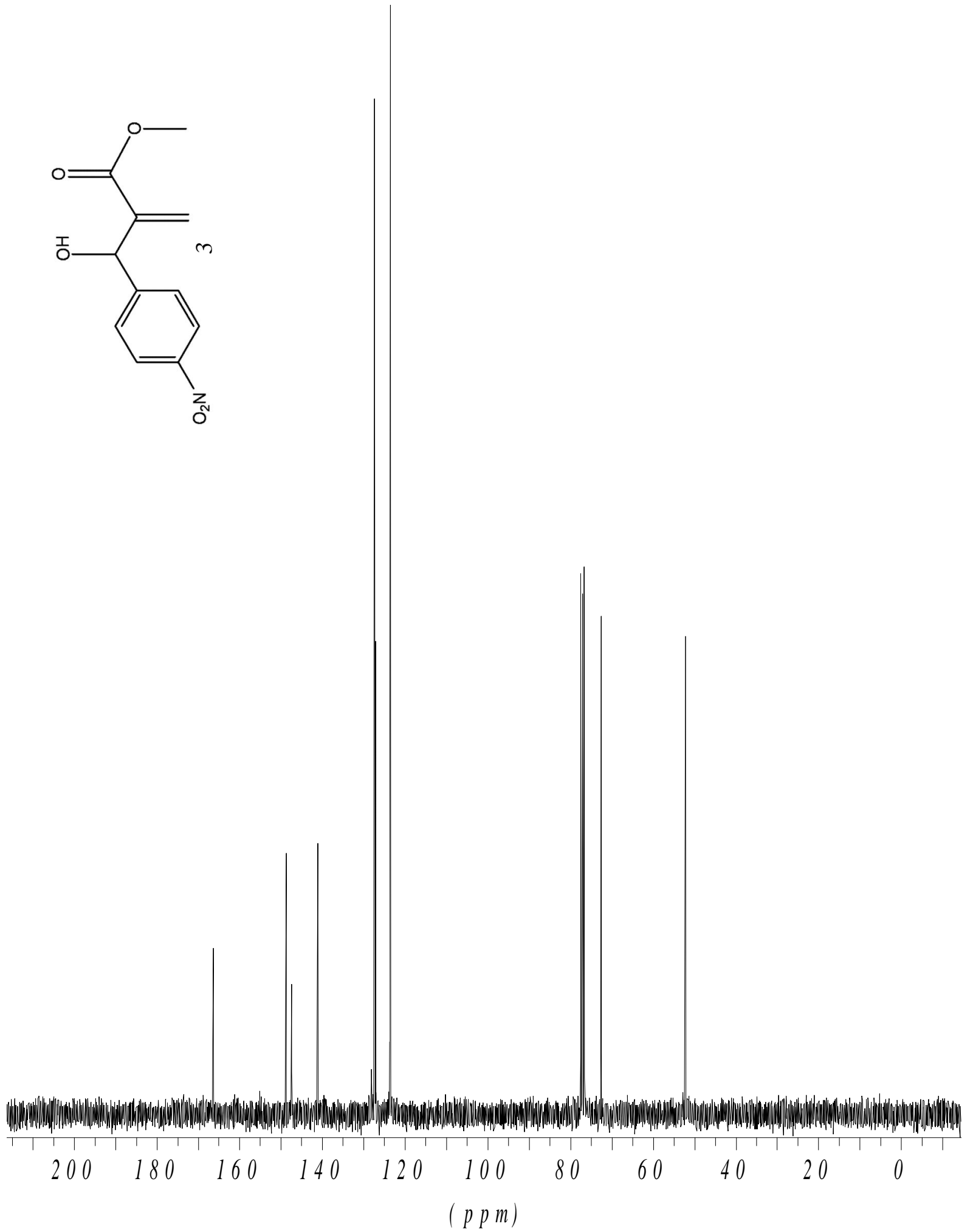




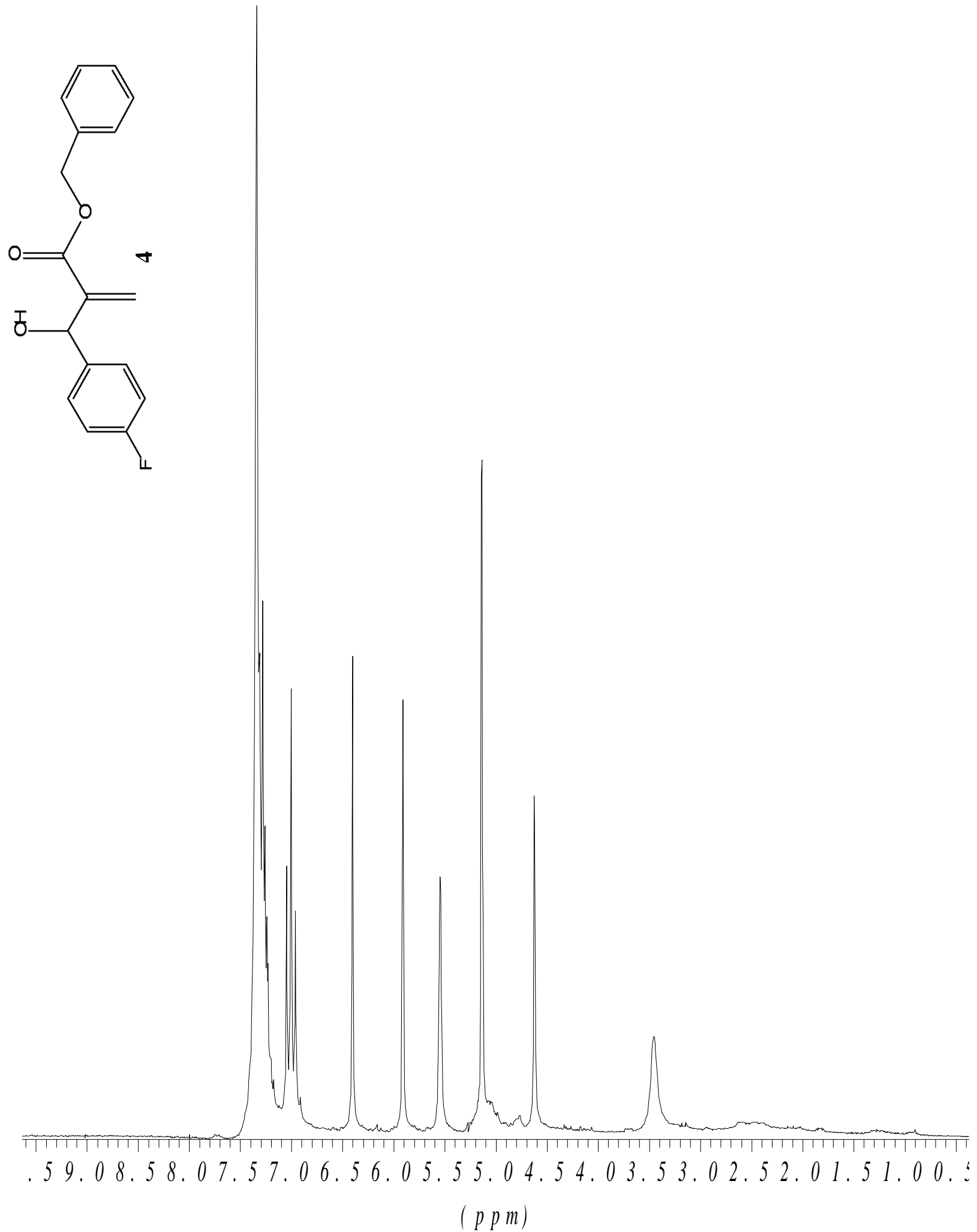



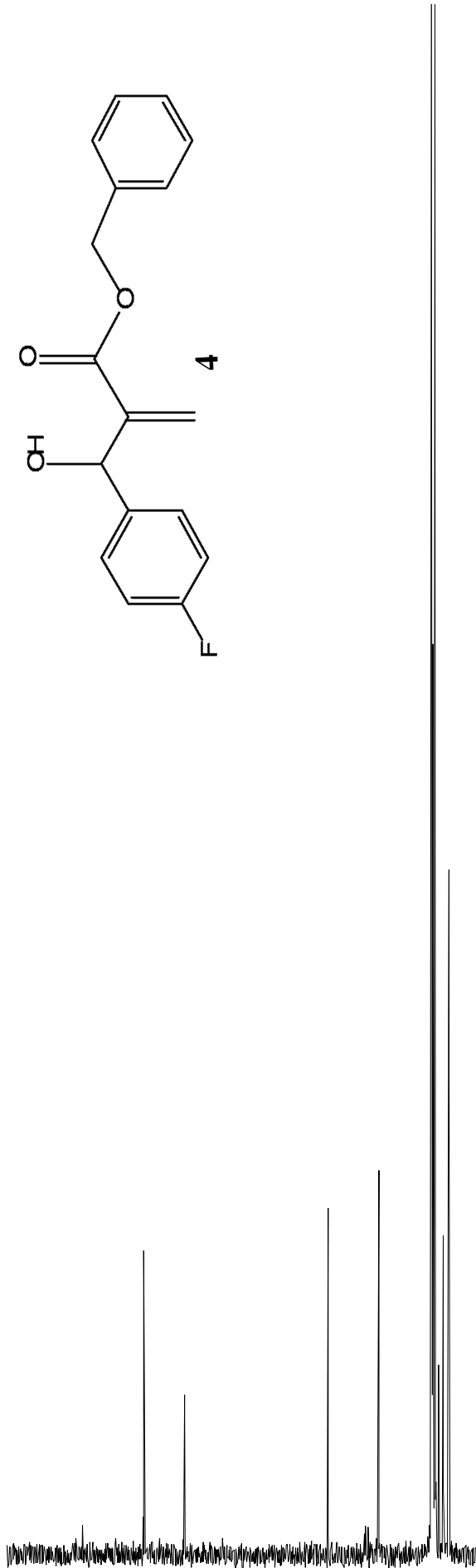

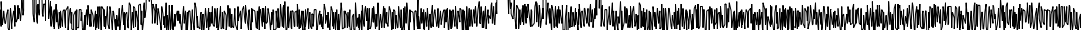

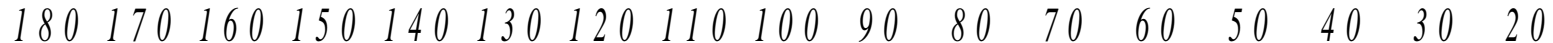
(ppm) 


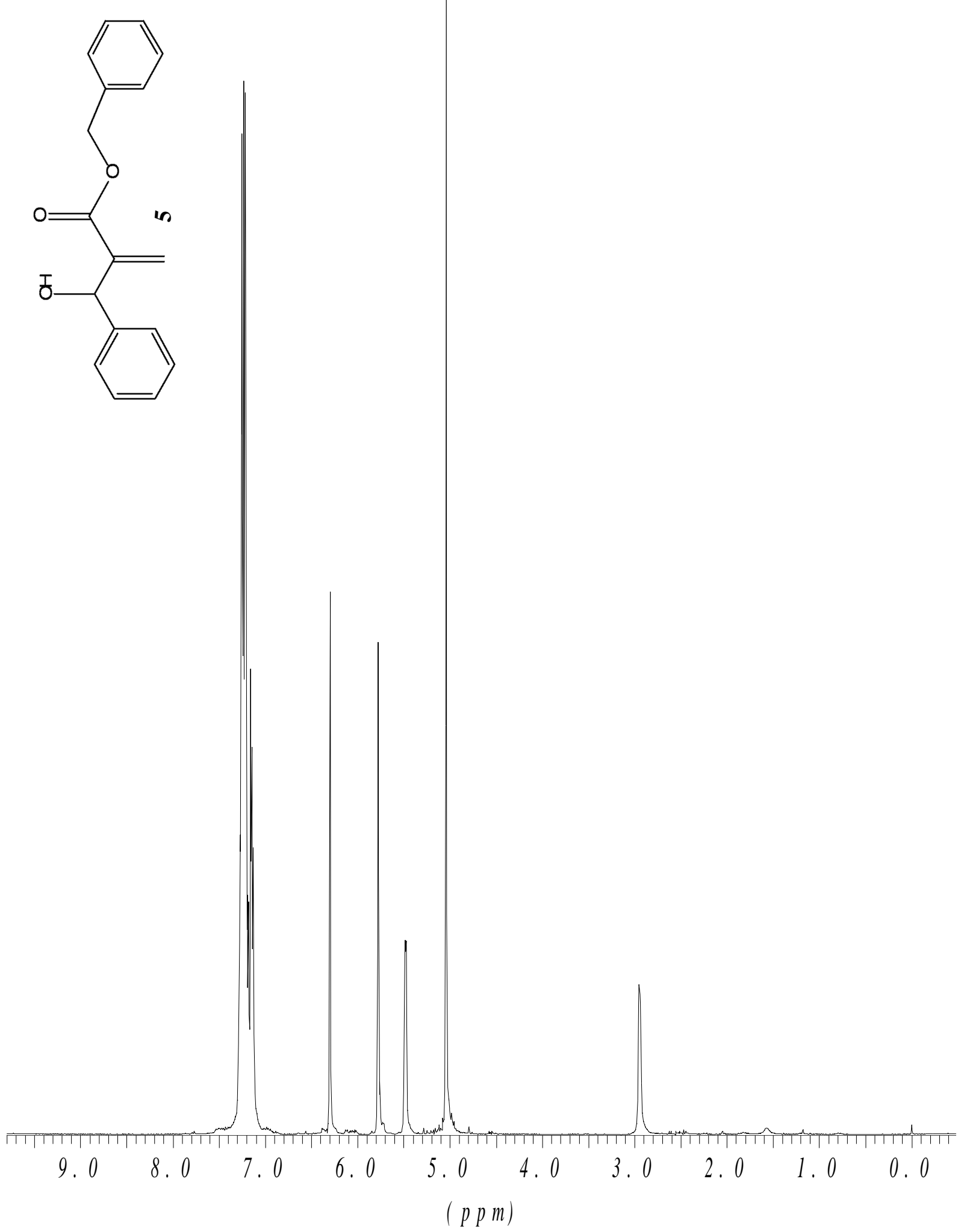




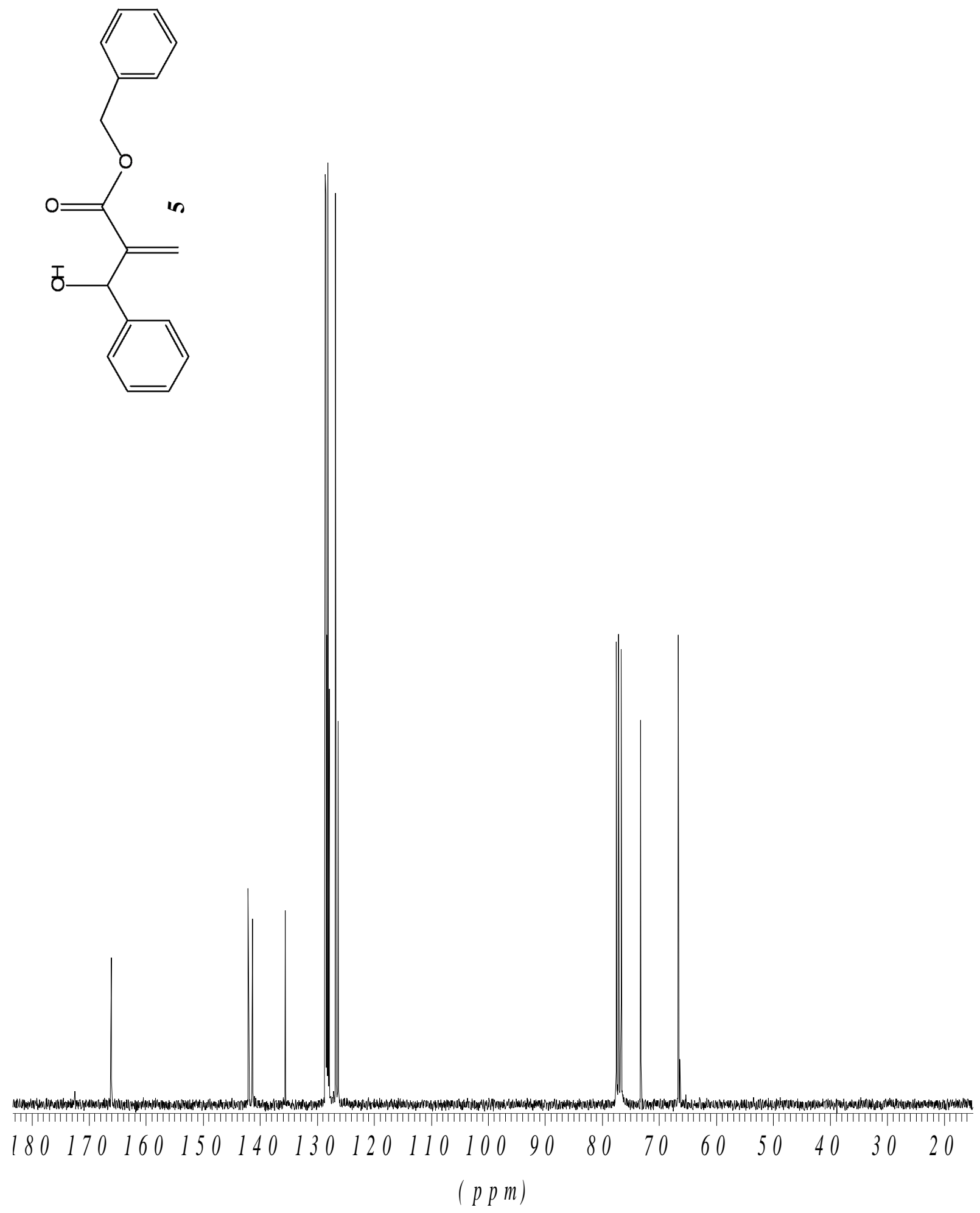




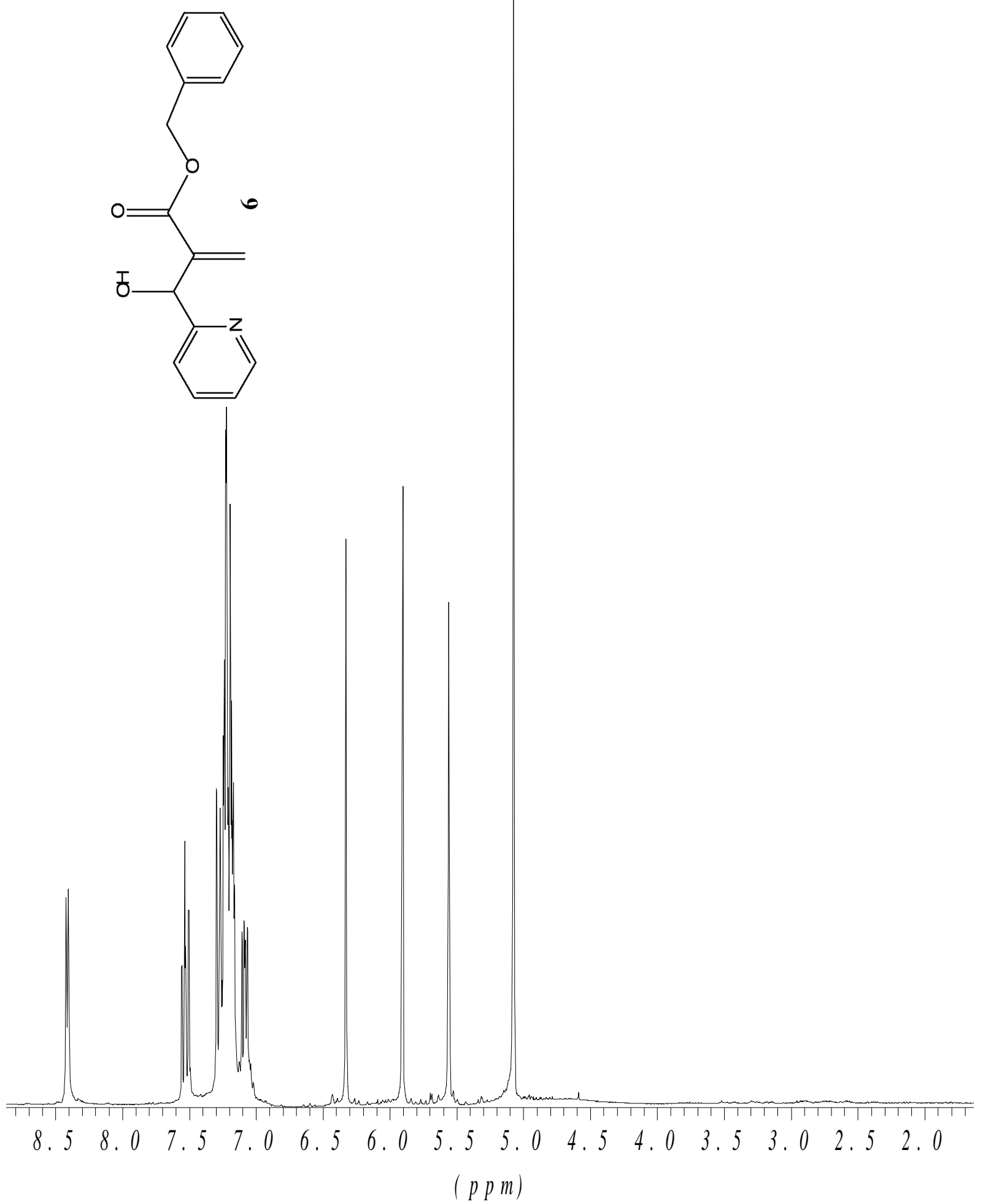




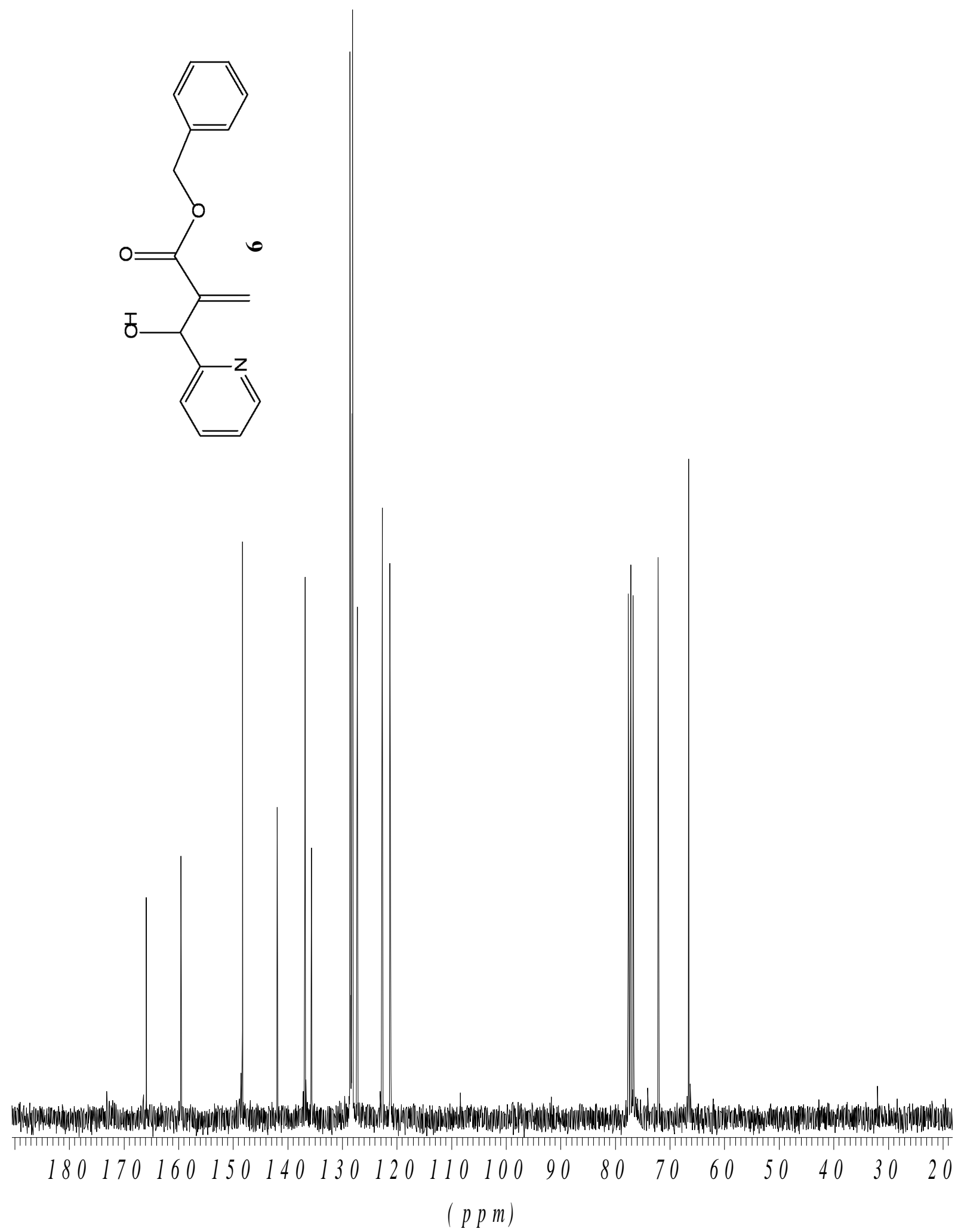




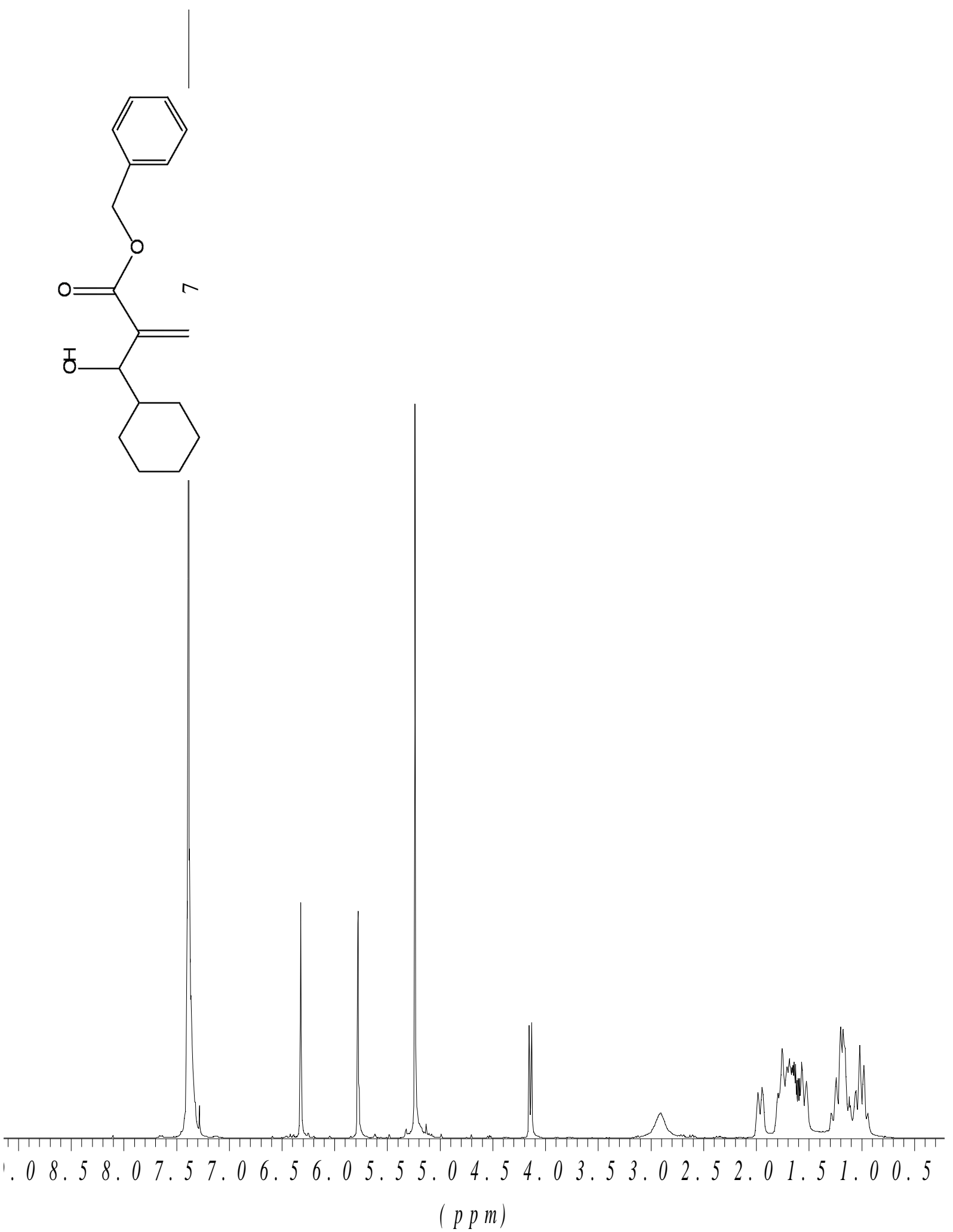




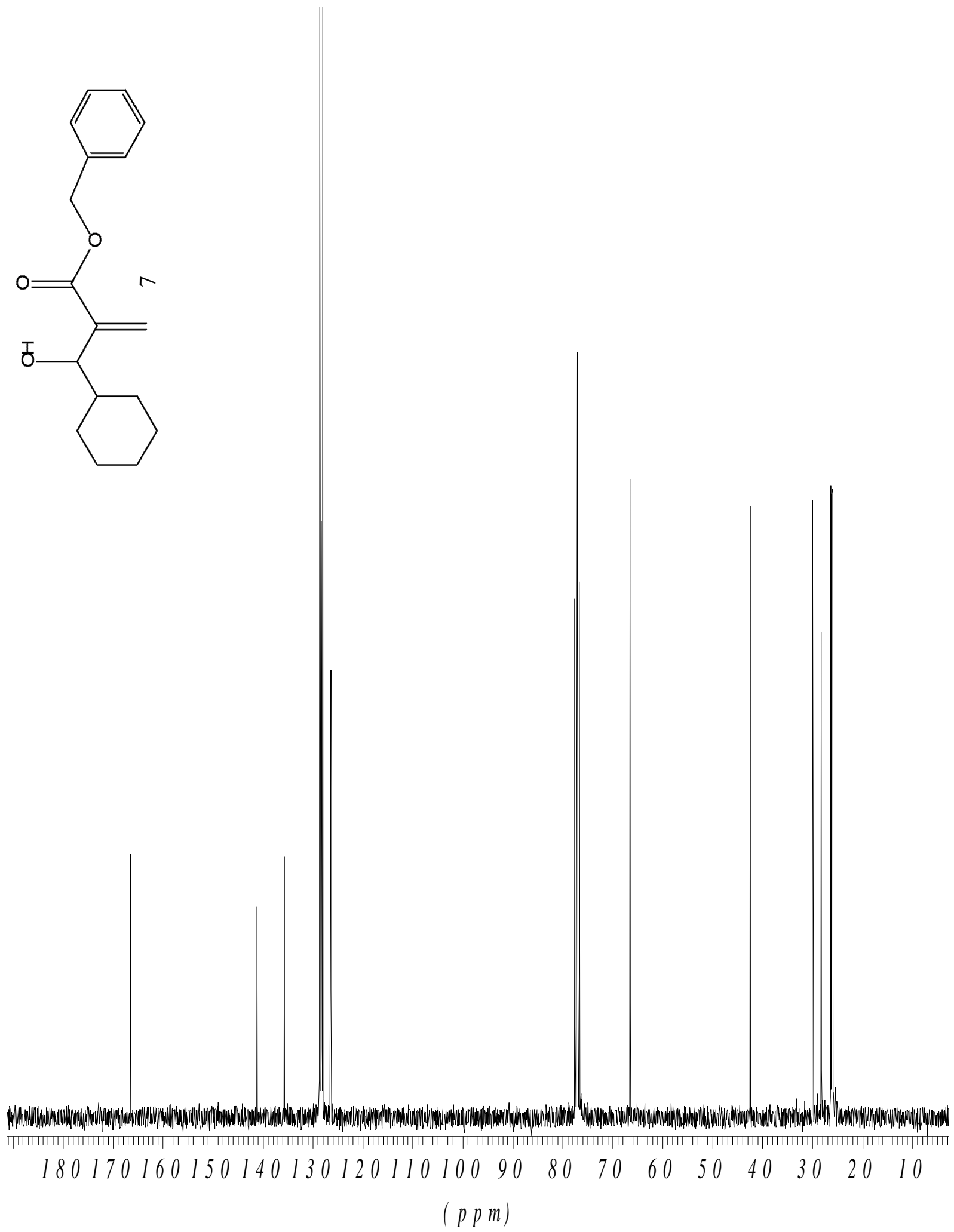




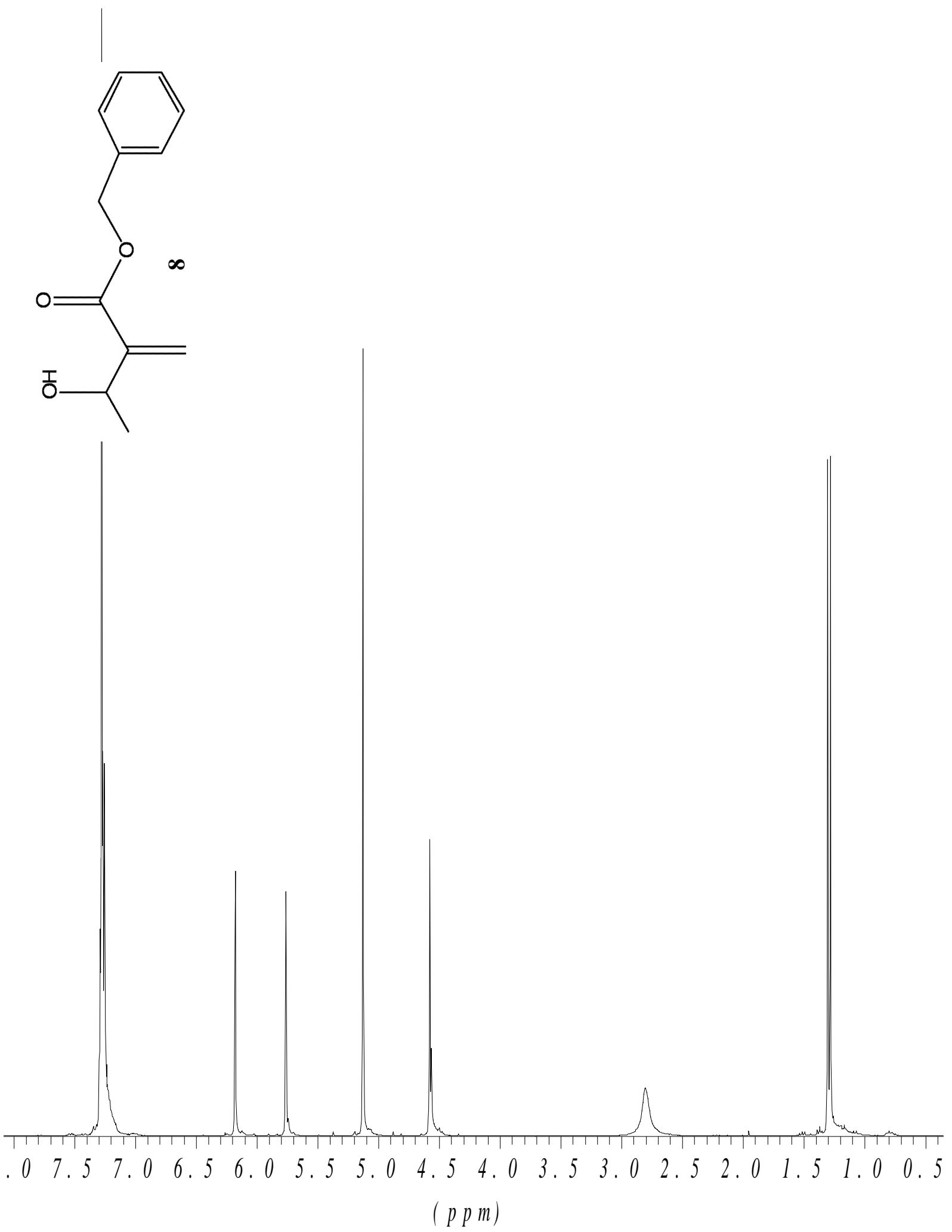



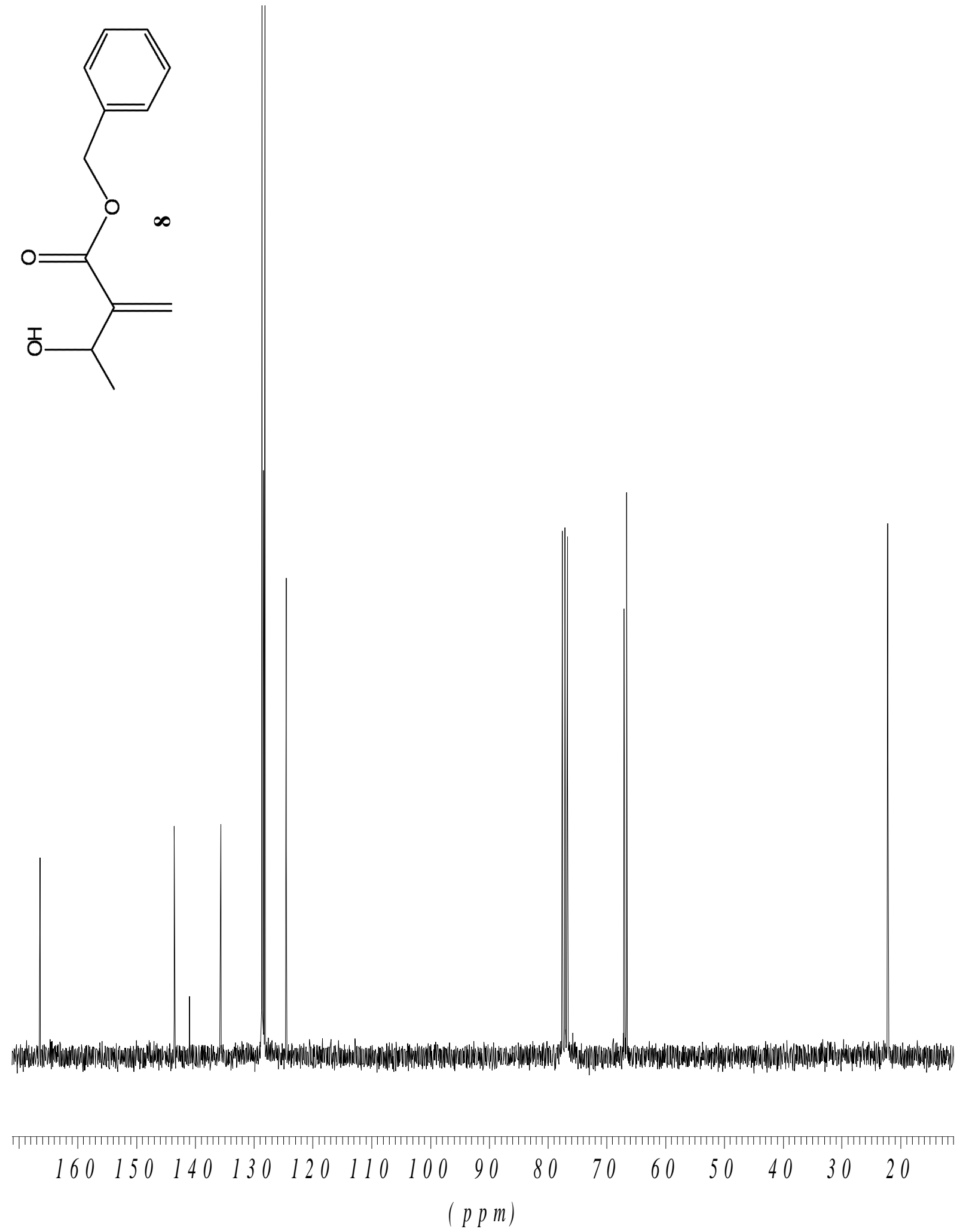